\title{
The Use of PELOD Score in Predicting Acute Kidney Injury in Critically ill Children
}

\author{
Prasetyo RV' ${ }^{1}$, Saraswati $\mathrm{PD}^{2}$, Kurniawan $\mathrm{MR}^{3}$, Kushartono $\mathrm{H}^{4}$, Soemyarso NA ${ }^{5}$, Azis $\mathrm{AL}^{6}$, Noer MS
}

${ }^{1}$ Dr. Risky Vitria Prasetyo, Division of Paediatric Nephrology, ${ }^{2}$ Dr. Putu Dian Saraswati, ${ }^{3} \mathrm{Dr}$. Muhammad Riza Kurniawan, Division of Paediatric Nephrology. ${ }^{4}$ Dr. Hari Kushartono, $\mathrm{PhD}$, Division of Paediatric Critical Care, ${ }^{5} \mathrm{Dr}$. Ninik Asmaningsih Soemyarso, PhD, Division of Paediatric Nephrology, ${ }^{6} \mathrm{Dr}$. Abdul Latief Azis, Division of Paediatric Critical Care, ${ }^{7}$ Professor, Dr. Mohammad Sjaifullah Noer, Division of Paediatric Nephrology.All from the Department of Child Health, Medical School, Airlangga University, Dr. Soetomo Hospital Surabaya Indonesia.

\section{Address for correspondence:}

Dr. Risky Vitria Prasetyo

Jalan Kertajaya Indah Tengah 6/14 (H-208)

Surabaya 60116, Indonesia

Tel No; +62 816507203

Email: kikiprasetyo1409@gmail.com

Acknowledgements: None

Funding: Nil

Conflict of Interest: None

Permission from IRB: granted from The Ethical Committee on Human Research Project Dr. Soetomo General Hospital Surabaya on December 10, 2013 (No. 305/Panke.KKE/ XII/2013)

Ethical dilemmas faced during study: None

\section{How to cite}

Prasetyo RV, Saraswati PD, Kurniawan MR, Kushartono $\mathrm{H}$, Soemyarso NA, Azis AL, Noer MS. The Use of PELOD Score in Predicting Acute Kidney Injury in Critically ill Children. J Nepal Paediatr Soc 2016;36(2):165-169.

doi: http://dx.doi.org/10.3126/jnps.v36i2.14624

This work is licensed under a Creative Commons Attribution 3.0 License.

\begin{abstract}
Introduction: Acute kidney injury (AKI) significantly increases morbidity and mortality in critically ill children. Prognostic indicators such as Pediatric Logistic Organ Dysfunction (PELOD) score is associated with factors related to renal dysfunction. The aim of this study was to study the AKI incidence and correlate the PELOD score with AKI in critically ill children admitted to PICU at Dr. Soetomo Hospital Surabaya Indonesia. Material and Methods: A prospective study was conducted to all children admitted to PICU during 15 January-14 April 2014. Demographic data (age, sex, PICU indications, PELOD scores, AKI staging by pRIFLE at admission) and outcome after 7 days at PICU were recorded. All data were analyzed descriptively $(p<0.05)$. Results: A total of $56(47.1 \%)$ out of 119 children were studied. The rest was excluded for being $<3$ months old, had end-stage kidney disease or complex cardiac problem, and cardiac catheterization. Mean age of subjects was 49.7 (SD 46.2) months, male-to-female ratio of 1.2:1. PICU indication was dominated by shock (35.7\%), followed by CNS dysfunction in $13(23.2 \%)$ and respiratory failure in 12 (21.4\%) children. AKI was noted in $15(26.8 \%)$ children, mostly $(10.7 \%)$ in Injury stage with $5(8.9 \%)$ in Risk and $4(7.1 \%)$ in Failure stages. PELOD scores at admission ranged from 0 to 20 (mean 4.34, SD 5.87), higher scores in AKI group (7.8 \pm 6.64 vs $3.1 \pm 5.09, \mathrm{P}=0.013)$. Twelve $(21.4 \%)$ children died, 7 (58.3\%) had AKI with $3(25.0 \%)$ each in Risk and Failure while $1(8.3 \%)$ in Injury $(p<0.05)$. Conclusion:PELOD score can be used as a predictor for AKI in critically ill children.
\end{abstract}

Key words: PELOD score, Acute kidney injury, Critically ill children

\section{Introduction}

A cute kidney injury (AKI) is a common problem that significantly increases morbidity and mortality in pediatric intensive care units (PICUs). Prognostic indicators used to describe disease severity, such as Pediatric Risk of Mortality (PRISM), Pediatric Index of Mortality II (PIM II) and Pediatric Logistic Organ Dysfunction (PELOD) scores, are associated with factors that markedly influence renal dysfunction'. The incidence of $A K I$ in this at-risk population remains unknown 
due to the lack of consensus on the definition of AKI with more than 30 different definitions of this disease exist in the literature. ${ }^{1}$ The Acute Dialysis Quality Initiative (ADQI) published RIFLE (Risk, Injury, Failure, Loss, End-stage) criteria in 2004 which delineate the important milestones for critically ill adult patients. The term Acute Kidney Injury (AKI) was proposed to cover the entire spectrum of this syndrome. Akcan-Arikan et al $(2007)^{2}$ developed a modified version of RIFLE for pediatric population ( $p$ RIFLE) based on a reduction in estimated creatinine clearance $(\mathrm{eCCl})$ while monitoring urine output based on body weight (figure 1). AKI is then characterized by a sudden and generally reversible renal function impairment involving inability to maintain the homeostasis and may or not be accompanied by reduced diuresis ${ }^{3}$.

Considering the close association between severely ill patients and $\mathrm{AKI}$, the quantification of ICU patient's severity is mandatory ${ }^{3}$. Severity scoring systems in the intensive care unit have been developed in response to an increased emphasis on the evaluation and monitoring of health care services ${ }^{4}$. In pediatrics, the most used prognostic indicators are PRISM, PIM and PELOD ${ }^{3}$. LOD model has been introduced by Le Gall et al in 1996 and uses a multiple logistic regression analysis on a large database. The six organ failures of the LOD are then defined and the statistical model gives a $0-5$ points weighting to each dysfunction ${ }^{5}$.A previous study by Vera et al $(2013)^{6}$ found that higher PELOD score was found in AKI group in 113 critically ill children.

There was a lack of study focusing on the outcome of the critically ill children using the PELOD score correlated to AKI by pRIFLE criteria. Therefore the aim of this study was to study the $\mathrm{AKI}$ incidence and correlate the PELOD score with AKI in critically ill children admitted to PICU at Dr. Soetomo Hospital Surabaya Indonesia.

\section{Material and Methods}

A prospective study on children admitted to PICU at Dr. Soetomo Hospital Surabaya Indonesia was done during 15 January to 14 April 2014 was conducted. Demographic data including age and sex, PICU indications, PELOD scores and AKI staging using
pRFILE criteria at PICU admission were recorded. The outcome of subjects were determined after 7 days at PICU.

All data were analyzed by descriptive statistics, chisquare and Fisher test. Cut off points of PELOD scores and receiver operating curve (ROC) were calculated by SPSS 21.0. A $p$ value $<0.05$ was considered statistically significant.

This study was approved by The Ethical Committee on Human Research Project at Dr. Soetomo Hospital.

\section{Results}

A total of 119 children were admitted to PICU during study period. Fifty six $(47.1 \%)$ of them were studied further and the other 63 children were excluded for being $<3$ months old, had end-stage kidney disease or complex cardiac problem, and children underwent cardiac catheterization. The characteristics of subjects included mean age of 49.7 (SD 46.2) months with maleto-female ratio of 1.2:1. Indication for PICU admission was dominated by shock (35.7\%), followed by central nervous system (CNS) dysfunction in 13 (23.2\%) and respiratory failure in $12(21.4 \%)$ children (table 1$)$.

AKI was noted in $15(26.8 \%)$ children, mostly $(10.7 \%)$ in Injury stage with $5(8.9 \%)$ in Risk and 4 (7.1\%) in Failure stages. PELOD scores at admission ranged from 0 to 20 with mean 4.34 (SD 5.87). There was a significant higher score found in AKI group (7.8 \pm 6.64 vs $3.1 \pm 5.09, p=0.013$ ) when compared to non-AKI group (table 2). A cut-off point for PELOD score to AKI of 6.0 was determined by ROC curve with sensitivity of $60 \%$, specificity of $75.6 \%$ and area under the curve (AUC) of 0.75 (figure 2). Subjects with PELOD score $>6.0$ had a significantly higher risk for $\mathrm{AKI}$ than subjects with PELOD score $<6.0(p=0.013)$ (table 3 and 4$)$.

Twelve (21.4\%) children died, 7 (58.3\%) had AKI with $3(25.0 \%)$ each in Risk and Failure stages while $1(8.3 \%)$ in Injury $(p<0.05)$. There was a significant difference on the outcome of subjects with AKI when compared to non-AKI group $(p=0.010)$. Each stage of $A K I$ had non-significant differences on the outcome $(p>0.05)$ (table 5). 
Table 1: Basic characteristics of subjects

\begin{tabular}{|c|c|c|c|}
\hline \multicolumn{2}{|c|}{ Characteristic } & \multirow{2}{*}{$\begin{array}{l}\mathbf{N} \\
14\end{array}$} & \multirow{2}{*}{$\begin{array}{c}\% \\
25.0\end{array}$} \\
\hline \multirow{4}{*}{ Age } & 3-12 month & & \\
\hline & $13-60$ month & 23 & 41.1 \\
\hline & $61-120$ month & 14 & 25.0 \\
\hline & $>120$ month & 5 & 8.9 \\
\hline \multirow{2}{*}{ Gender } & Male & 30 & 53.6 \\
\hline & Female & 26 & 46.4 \\
\hline \multirow{7}{*}{$\begin{array}{l}\text { Indication } \\
\text { for PICU } \\
\text { admission }\end{array}$} & Shock & 20 & 25.7 \\
\hline & CNS dysfunction & 13 & 23.2 \\
\hline & Respiratory failure & 12 & 21.4 \\
\hline & Heart failure & 6 & 10.7 \\
\hline & $\begin{array}{l}\text { Respiratory and CNS } \\
\text { dysfunction }\end{array}$ & 2 & 3.6 \\
\hline & Post surgery & 2 & 3.6 \\
\hline & $\begin{array}{l}\text { Respiratory and heart } \\
\text { failure }\end{array}$ & 1 & 1.8 \\
\hline \multirow{2}{*}{ Outcome } & Alive & 44 & 78.6 \\
\hline & Died & 12 & 21.4 \\
\hline
\end{tabular}

Table 2: Distribution of PELOD scores and AKI staging in subjects

\begin{tabular}{lccc}
\hline PELOD Score & & Mean (SD) & p \\
\hline \multirow{3}{*}{ AKI } & Total & $7.8(6.64)$ & \\
\cline { 2 - 3 } & Risk & $1.0(0.71)$ & \\
\cline { 2 - 3 } & Injury & $10.2(0.41)$ & \\
\cline { 2 - 3 } & Failure & $12.8(9.14)$ & \\
\cline { 2 - 3 } Non AKI & & $3.1(5.09)$ & \\
\hline
\end{tabular}

*significant chi-square test $(p<0.05)$
Table 3: Cut off point of PELOD score and AKI in subjects

\begin{tabular}{cccc}
\hline $\begin{array}{c}\text { Cut off point of } \\
\text { PELOD score }\end{array}$ & $\begin{array}{c}\text { AKI } \\
(\mathbf{n}(\%)\end{array}$ & $\begin{array}{c}\text { Non-AKI } \\
(\mathbf{n}(\%))\end{array}$ & p \\
\cline { 1 - 3 }$<6.0$ & $6(16.2)$ & $31(83.8)$ & \\
\cline { 1 - 3 } & $0.013^{*}$ \\
\hline
\end{tabular}

*significant chi square test $(P<0.05)$

Table 4: Cut off point of PELOD score and AKI staging in subjects

\begin{tabular}{cccc}
\hline $\begin{array}{c}\text { Cut off point of } \\
\text { PELOD score }\end{array}$ & $\begin{array}{c}\text { AKI-R } \\
(\mathbf{n}(\%)\end{array}$ & $\begin{array}{c}\text { AKI-I } \\
(\mathbf{n}(\%))\end{array}$ & $\begin{array}{c}\text { AKI-F } \\
(\mathbf{n}(\%))\end{array}$ \\
\hline$<6.0$ & $5(100.0)$ & $0(0.0)$ & $\begin{array}{c}1 \\
(25.0)\end{array}$ \\
$\geq 6.0$ & $0(0.0)$ & $6(100.0)$ & $\begin{array}{c}3 \\
(75.0)\end{array}$ \\
\hline
\end{tabular}

Table 5: Outcome of AKI subjects

\begin{tabular}{lcccc}
\hline AKI & & $\begin{array}{c}\text { Alive }(\mathbf{n} \\
(\%))\end{array}$ & $\begin{array}{c}\text { Died }(\mathbf{n} \\
(\%))\end{array}$ & p \\
\cline { 1 - 4 } AKI & Yes & $8(53.3)$ & $7(46.7)$ & \multirow{2}{*}{$0.010^{*}$} \\
\cline { 2 - 4 }$(\mathrm{n}=56)$ & No & $36(87.8)$ & $5(12.2)$ & \\
\cline { 2 - 5 } AKI & Risk & $2(40.0)$ & $3(60.0)$ & $0.242^{* *}$ \\
\cline { 2 - 5 } staging & Injury & $5(83.3)$ & $1(16.7)$ & $0.226^{* * *}$ \\
\cline { 2 - 5 }$(\mathrm{n}=15)$ & Failure & $1(25.0)$ & $3(75.0)$ & $1.000^{* * * *}$ \\
\hline
\end{tabular}

*significant Fisher test $(p<0.05)$

** non-significant Fisher test for risk and injury groups $(p>0.05)$

*** non-significant Fisher test for injury and failure groups $(p>0.05)$

**** non-significant Fisher test for risk and failure groups $(p>0.05)$

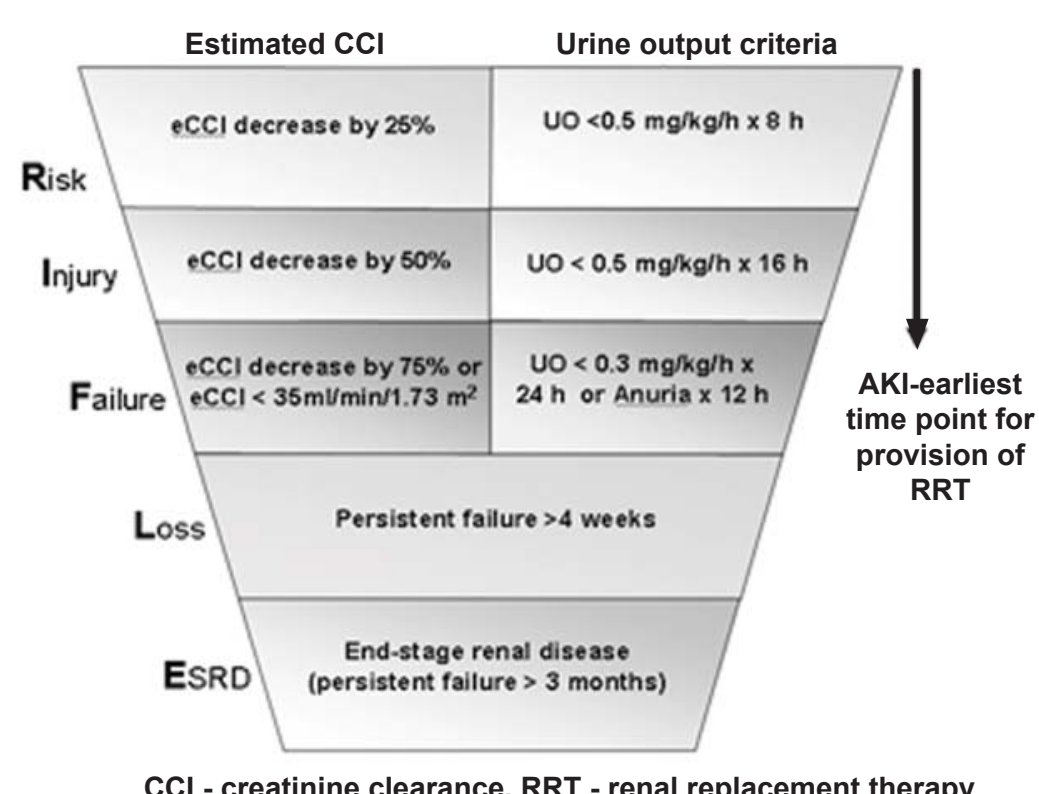

Fig 1: pRIFLE criteria for AKI(Akcan-Arikan A, Zappitelli M, Loftis LL, Washburn KK, Jefferson LS, Goldstein SL. Modified RIFLE criteria in critically ill children with acute kidney injury. Kidney Int 2007; 71: 1028-35.) 


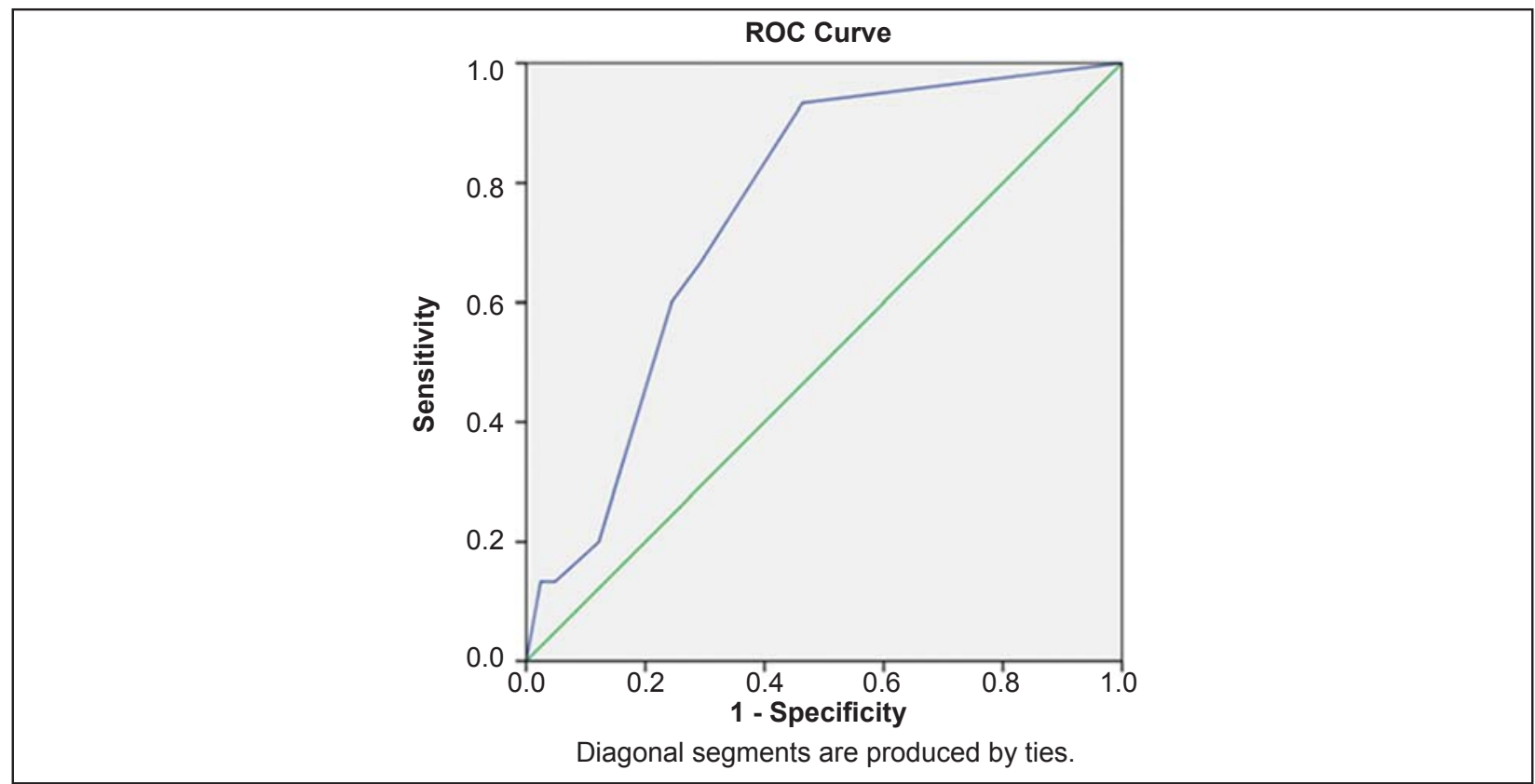

Fig 2: ROC curve of the study (A cut-off point for PELOD score to AKI of 6.0 was determined by ROC curve with sensitivity of $60 \%$, specificity of $75.6 \%$ and area under the curve (AUC) of 0.75 )

\section{Discussion}

The assessment of morbidity during ICU stay may provide important information about a patient's illness, their response to treatment and describe the patient population in clinical trials. PELOD is one of the popular model in common use throughout the world for organ dysfunction assessment. It was designed as a tool for evaluation on the probability of mortality based on organ dysfunction on the day of ICU admission ${ }^{5}$. AKI has a known catastrophic impact on critically ill patients. It is common among them and its cause is mostly multifactor. AKI may progress to renal failure, preventing the kidneys to play their most important role in maintaining homeostasis ${ }^{3}$.

In this study, the AKI incidence was $26.8 \%$ in PICU children, similar to other studies that ranged from 30 $80 \% \%^{2,3,6,7}$. Other adult studies found the incidence to be ranged from $30-60 \%, 8,9,10$. Regarding the AKI staging, the maximal pRIFLE score found during the patients stay was $33.3 \%$ R, $40.0 \%$ I, 26.7\% F, while Freire et al found $39.1 \%$ R, 39.1\% I, 21.8\% F; Akcan-Arikan et al found 48.8\% R, 26.0\% I, 25.2\% F; and Plötz et al found $52.0 \%$ $\mathrm{R}, 37.0 \% \mathrm{I}, 11.0 \% \mathrm{~F}$ respectively $\mathrm{y}^{2,3,7}$. The variable AKI incidences can be explained by the different populations studied, and also by the different ICU characteristics ${ }^{3}$.

The present study showed that the PELOD score correlated well with the AKI incidence in critically ill children admitted to PICU. A cut-off point of 6.0 was determined with AUC $0.75(>0.50)$ that revealed that it has a good discrimination. The AUC for the original PELOD was 0.84 with the subsequent studies showed results ranged from 0.7 to $0.8^{5}$.

Organ dysfunction is a dynamic process and the degree of dysfunction may vary with time and treatment. Serial or repetitive assessment of organ dysfunction scores allow for a more effective representation of an outcome prediction than does a single measurement ${ }^{5}$. Studies using the RIFLE and pRIFLE criterias in adults and children validated a positive statistically significant association between time of stay, both in ICU or hospital, and AKI proving a poorer prognosis predictor in critically ill patients ${ }^{3}$. In view of mortality rate, several studies have clearly shown that any degree of AKI is a poor prognosis indicator for critically ill patients. In this study, we found that there was a statistically significant higher mortality rate in AKI group when compared to non-AKI group. Freire et al found a ten times bigger of in-hospital mortality in AKI group; while Akcan-Arikan et al found no statistically significant difference on both groups; and Plotz et al identified a five times bigger mortalityin patients with any level of $\mathrm{AKI}^{2,3,7}$.

Several limitations were acknowledged in this study. First, studying in only a single centre put limitations on the case-mix and quality of ICU care. Secondly, evaluation of a single assessment of organ dysfunction scores after the the first 24 hours of ICU admission may not be so accurate. It would certainly be 
better to have serial measurements for the evaluation of organ dysfunction scores for predicting the outcome in critically ill patients.

\section{References}

1. Bresolin N, Bianchini AP, Haas CA. Pediatric acute kidney injury assessed by pRIFLE as a prognostic factor in the intensive care unit. Pediatr Nephrol 2013;28:485-92.

2. Akcan-Arikan A, Zappitelli M, Loftis LL, Washburn KK, Jefferson LS, Goldstein SL. Modified RIFLE criteria in critically ill children with acute kidney injury. Kidney Int 2007;71:1028-35.

3. Freire KMS, Bresolin NL, Fazah ACF, Carvalho FLC, Góes JEC. Acute kidney injury in children: incidence and prognostic factors in critically ill patients. Rev Bras Ter Intensiva 2010;22:166-74.

4. Tang $\mathrm{CH}$, Yang CM, Chuang $\mathrm{CY}$, Chang ML, Huang YC, Huang CF. A comparative study of clinical severity scoring systems in ICUs in Taiwan. Tzu Chi Med J 2005;17:239-45.

5. Khwannimit B. A comparison of three organ dysfunction scores: MODS, SOFA and LOD for predicting ICU mortality in critically ill patients. J Med Assoc Thai 2007;90:1074-81.

6. Vera R, Triratna S, Bahrun D, Theodorus. Hubungan acute kidney injury dan skor Pelod pada pasien penyakit kritis. Sari Pediatr 2013;15:181-5.

7. Plötz FB, Hulst HE, Twisk JW, Bökenkamp A, Markhorst DG, van Wijk JA. Effect of acute renal failure on outcome in children with severe septic shock. Pediatr Nephrol 2005;20:1177-81.

\section{Conclusion}

PELOD score can be used as a predictor for higher mortality rate in critically ill children with AKI.

8. Ostermann M, Chang RWS. Acute kidney injury in the intensive care unit according to RIFLE. Crit Care Med 2007;35:1837-43.

9. Hoste EA, Chermont G, Kersten A, Venkataraman R, Angus DC, De Bacquer D, Kellum JA. RIFLE criteria for acute kidney injury are associated with hospital mortality in critically ill children: a cohort analysis. Crit Care 2006;10:R204-12.

10. Bagshaw SM, George C, Dinu I, Bellomo R. A multicentre evaluation of the RIFLE criteria for early acute kidney injury in critically ill patients. Nephrol Dial Transplant 2008;23:1203-10.

11. Uchino S, Kellum JA, Bellomo R, Doig GS, Morimatsu $\mathrm{H}$, Morgera $\mathrm{S}$, et al. Acute renal failure in critically ill patients: a multinational, multicenter study. JAMA 2005;294:813-8.

12. Hui WF, Chan WKY, Miu TY. Acute kidney injury in the paediatric intensive care unit: identification by modified RIFLE criteria. Hong Kong Med $\mathrm{J}$ 2013;19:13-9.

13. Rapsang AG, Shyam DC. Scoring systems in the intensive care unit: a compendium. Indian J Crit Care Med 2014;18:220-8.

14. Bhadoria $P, B$ Bagwat $A G$. Severity scoring systems in paediatric intensive care units. Indian $J$ Anaesth 2008;S5:663-75.

15. Thukral A, Kohli U, Lodha R, Kabra SK, Arora NK. Validation of the PELOD score for multiple organ dysfunction in children. Indian Ped 2007;44:683-6. 